\title{
The effect of aspirin and nonsteroidal anti-inflammatory drug use after diagnosis on survival of oesophageal cancer patients
}

\author{
Jente van Staalduinen ${ }^{1}$, Martine Frouws ${ }^{1}$, Marlies Reimers ${ }^{1}$, Esther Bastiaannet ${ }^{1,2}$, Myrthe P P van Herk-Sukel ${ }^{3}$,
} Valery Lemmens ${ }^{4,5}$, Wobbe $\mathrm{O}$ de Steur ${ }^{1}$, Henk H Hartgrink ${ }^{1}$, Cornelis J H van de Velde ${ }^{1}$ and Gerrit-Jan Liefers ${ }^{\star}, 1$

\begin{abstract}
${ }^{1}$ Department of Surgery, Leiden University Medical Center, Leiden, The Netherlands; ${ }^{2}$ Department of Gerontology \& Geriatrics, Leiden University Medical Center, Leiden, The Netherlands; ${ }^{3}$ PHARMO Institute for Drug Outcomes Research, Utrecht, The Netherlands; ${ }^{4}$ Department of Research, Comprehensive Cancer Centre Netherlands, Eindhoven, The Netherlands and ${ }^{5}$ Department of Public Health, Erasmus MC University Medical Centre, Rotterdam, The Netherlands
\end{abstract}

Background: Aspirin use has been shown to lower incidence and mortality in cancer patients. The aim of this population-based study was to determine the effect of postdiagnosis low-dose aspirin use on survival of patients with oesophageal cancer.

Methods: Patients with oesophageal cancer (1998-2010) were selected from the Eindhoven Cancer Registry and linked with outpatient pharmacy data regarding aspirin and nonsteroidal anti-inflammatory drugs (NSAIDs). Users were subdivided into both prediagnosis and postdiagnosis or only postdiagnosis users. Parametric survival models with an exponential (Poisson) distribution were used with non-specific death as endpoint.

Results: In this study 560 patients were included. Overall, 157 patients (28.0\%) were non-users, 293 patients (52.3\%) pre- and postdiagnosis (89 aspirin and 204 NSAID users) and 110 patients (19.6\%) only postdiagnosis users (16 aspirin and 94 NSAID users). Postdiagnosis aspirin use was associated with overall survival (RR 0.45 ( $95 \% \mathrm{Cl} 0.34-0.60 ; P<0.001$ ); adjusted rate ratio was 0.42 (95\% Cl: $0.30-0.57 ; P<0.001)$. Postdiagnosis use of NSAIDs was associated with overall survival (RR 0.61 (95\% Cl 0.49-0.76; $<0.001)$; however, adjusted analyses did not show a significant association with a rate ratio of $0.84(95 \% \mathrm{Cl} 0.66-1.07 ; P=0.2)$.

Conclusions: Our study shows that postdiagnosis aspirin use might be associated with a higher survival rate in oesophageal cancer patients. A randomised clinical trial is needed to verify our observations of possible postdiagnosis aspirin use benefit.

In 2008 an estimated 482300 new oesophageal cancer cases and 406800 oesophageal cancer deaths occurred worldwide (Jemal et al, 2011). Prognosis of patients with oesophageal cancer is poor; the 10 -year survival rate in all patients is $\sim 14 \%$ (Dubecz et al, 2012). Regular use of aspirin and other nonsteroidal antiinflammatory drugs (NSAIDs) has been shown to have a chemopreventive effect on the incidence of multiple cancers (Din et al, 2010; Langley et al, 2011; Algra and Rothwell, 2012; Huang et al, 2014), including oesophageal cancer (Jayaprakash et al, 2006; Sadeghi et al, 2008; Abnet et al, 2009). In a meta-analysis by Corley
DA et al regular aspirin and NSAID use showed a protective association with oesophageal cancer, with summary odds ratios (95\% CI) of $0.50(0.38-0.66)$ and $0.75(0.54-1.00)$, respectively (Corley et al, 2003). Also, regular use of aspirin has been shown to have therapeutic effects on the overall and cancer-specific survival of several types of cancers (Din et al, 2010; Algra and Rothwell, 2012; Bastiaannet et al, 2012).

Aspirin and NSAIDs are inhibitors of prostaglandin endoperoxide synthase 1 and 2 (also known as COX1,2); enzymes involved in the formation of prostaglandins. However, the exact biological

*Correspondence: Dr G-J Liefers; E-mail: g.j.liefers@lumc.nl

Received 18 November 2015; revised 31 January 2016; accepted 14 February 2016; published online 7 April 2016

(c) 2016 Cancer Research UK. All rights reserved 0007 - 0920/16 
mechanisms involved in the anticancer effects of aspirin are still unknown. Low-dose use of aspirin irreversibly inhibits the constitutive COX1 expression of circulating platelets. Only highdose and frequent aspirin use is believed to be capable of inhibiting the induced COX2 expression in systemic tissues (Bruno et al, 2012). The expression of COX 2 has been shown to be upregulated in most oesophageal tumours and has prognostic significance (Zimmermann et al, 1999; Buskens et al, 2002). Experimental data also showed that inhibition of COX2 expression inhibits cell proliferation and induces apoptosis in human oesophageal squamous cell carcinoma in vitro (Zhang et al, 2011). Furthermore, aspirin has been demonstrated to have COX-independent effects on tumour cells (Dovizio et al, 2013).

Consequently, aspirin and other non-steroid anti-inflammatory drugs could have an effect on cancer-specific survival and overall survival. Cancer-specific survival could be affected not only by taking aspirin after diagnosis owing to the mimicking of adjuvant therapy in order to prevent metastases, but also on overall survival as the cancer-related mortality of oesophageal cancer is high. A preliminary experimental study showed a beneficial effect of postoperative use of aspirin on the survival of patients with oesophageal cancer; the 5-year survival for the aspirin users was $51.2 \%$, for the placebo group $41.0 \%$ and for the patients who used no tablets it was $42.3 \%$ ( $P=0.04$ or $P=0.029$ when the last two groups were combined) (Liu et al, 2009); however, the results are still indecisive as no significant survival gain was observed in the any of the TNM-staging groups. The effect of postdiagnosis use of aspirin and NSAIDs on overall survival of oesophageal cancer has not been studied in a population-based study yet. Therefore, the aim of this observational study is to determine the effect of postdiagnosis use of aspirin and NSAIDs on the overall survival of patients with oesophageal cancer, using a combined database of registered drug use and data from a regional cancer registry (van Herk-Sukel et al, 2010).

\section{MATERIALS AND METHODS}

The Eindhoven Cancer Registry (ECR) is maintained by the Comprehensive Cancer Centre Netherlands and comprises information on newly diagnosed cancer patients in the southeastern part of the Netherlands. The ECR is served by 10 hospitals in an area of $\sim 2,4$ million inhabitants. Patients diagnosed with oesophageal cancer between 1998 and 2010 were selected from the ECR with no exclusion criteria. Patients are informed about the registration and registered unless the patient has objected to be registered. The Netherlands Cancer Registry is obliged to work according to the law about protection of privacy data; consent of the patients for this specific study was not applicable. The data from the ECR were linked to the central patient database of the PHARMO Database Network as described elsewhere (van HerkSukel et al, 2010). Data regarding the dispensing of aspirin and NSAIDs (a single dispensing for aspirin was usually for 90 days, for NSAIDs 30 days) were extracted from the Outpatient Pharmacy Database of the PHARMO Database Network. Linkage of cancer registry data with the municipal population registries, which document the vital status of their inhabitants, resulted in a reliable vital status of every patient.

Definition of user. Dispensings of aspirin and NSAIDs were extracted from the PHARMO Outpatient Pharmacy Database (see Supplementary Table 1). The majority of dispensings of lowdose aspirin was $80 \mathrm{mg}$ (98.1\%); $30 \mathrm{mg}$ aspirin was only dispensed 92 times from a total of 4835 dispensings (1.9\%). Users were defined as patients who had at least one dispensing for aspirin or NSAIDs for at least 14 days. Patients were classified as non-users if they used any dispensed aspirin or NSAIDs for $<14$ days.
Frequent users were defined as users that had $\geqslant 30$ or $\geqslant 45$ dispensings. Besides, we defined a subgroup of frequent users who had $>20$ dispensings solely postdiagnosis, irrespective of the number of dispensings prediagnosis.

In order to divide the users into subgroups, the date of dispensing was compared with the date of diagnosis. Subsequently, users were subdivided into both prediagnosis (use of aspirin or NSAIDs at any time or duration before cancer diagnosis) and postdiagnosis users, only postdiagnosis users, and a group containing both groups (postdiagnosis users). Patients were defined as 'only postdiagnosis' if they started using medication for at least 14 days after diagnosis. Patients were classified as 'prediagnosis and postdiagnosis' users if they used a medication before diagnosis and still used that medication for at least 14 days after diagnosis. 'Postdiagnosis users' were defined as pre- and postdiagnosis users and only postdiagnosis users combined; thus it includes all postdiagnosis users, irrespective of when they started the aspirin or NSAIDs. Some patients $(n=113)$ had both dispensings for aspirin and (other) NSAIDs; they were included in the aspirin group when the number of dispensings for aspirin exceeded the number of dispensings for NSAIDs and vice versa if the number of dispensings for NSAIDs exceeded the number of dispensings for aspirin.

Definition of follow-up time. Because the PHARMO Outpatient Pharmacy database comprises GP or specialist prescribed healthcare products dispensed by the outpatient pharmacy, so drug use of discharged patients, follow-up time started from 14 days after diagnosis (T0) of the oesophageal cancer and ended at the last contact date or time of death. Consequently, all patients who died within 14 days before T0 were excluded. Time to first dispensing was defined as the time from T0 to the date of the first dispensing.

Survival analysis. In the overall survival analysis with timedependent exposure of aspirin or NSAIDs, patients were defined as non-users from T0 to the date of first use of aspirin or NSAIDs and user from date of first use to the last contact or time of death. To analyse the association of aspirin or NSAID use on overall survival, parametric survival models with exponential (Poisson) distribution were used. Non-specific death was coded as event in the survival analyses. Univariable analyses were performed to assess the association between aspirin or NSAID use and overall survival and multivariable models were built to adjust for sex, age, histological type, location of the tumour, comorbidity, grade, stage, surgery, chemotherapy and radiotherapy. It was possible to adjust for the presence of the following comorbidities: lung diseases, other types of cancer, cardiovascular diseases, hypertension, cerebrovascular accidents, digestive diseases and diabetes. We adjusted for these comorbidities by grouping the comorbidities in none or at least one comorbidity. Furthermore, the survival analysis was stratified for postdiagnosis aspirin users in prediagnosis and postdiagnosis, only postdiagnosis users and a combined group.

\section{RESULTS}

In this observational study 560 patients diagnosed with oesophageal cancer from 1998 to 2010 were included with a follow-up until December 2011. The patient and tumour characteristics of this cohort are shown in Table 1. Median age at diagnosis was 66 years (interquartile range 23-97). Overall, $76 \%$ of the patients were males $(n=423)$ and $24 \%$ were females $(n=137)$. In total, $59 \%$ of the patients were diagnosed with adenocarcinoma $(n=330)$ and $33 \%$ of the patients were diagnosed with squamous cell carcinoma $(n=190)$. From all patients 157 patients $(28 \%)$ were non-users of any dispensed aspirin and NSAIDs. In total, 204 patients (36\%) and 89 patients $(16 \%)$ used NSAIDs or aspirin both prediagnosis 
Table 1. Characteristics of the oesophageal cancer patients included in the cohort

\begin{tabular}{|c|c|c|}
\hline Variable & Number & Percentage \\
\hline \multicolumn{3}{|l|}{ Sex } \\
\hline Male & 423 & 75.5 \\
\hline Female & 137 & 24.5 \\
\hline \multicolumn{3}{|l|}{ Age } \\
\hline$<60$ & 164 & 29.3 \\
\hline $60-70$ & 173 & 30.9 \\
\hline $70-80$ & 153 & 27.3 \\
\hline $80+$ & 70 & 12.5 \\
\hline \multicolumn{3}{|l|}{ Histological type } \\
\hline SCC & 190 & 33.9 \\
\hline$A C$ & 330 & 58.9 \\
\hline Squamo-adenocarcinoma & 5 & 0.9 \\
\hline Other & 35 & 6.3 \\
\hline \multicolumn{3}{|l|}{ Localisation } \\
\hline Upper third & 23 & 4.1 \\
\hline Middle third & 83 & 14.8 \\
\hline Lower third & 420 & 75.0 \\
\hline GE-junction & 16 & 2.9 \\
\hline Cervical & 10 & 1.8 \\
\hline Unknown & 8 & 1.4 \\
\hline \multicolumn{3}{|l|}{ Stage } \\
\hline 1 & 45 & 8.0 \\
\hline II & 89 & 15.9 \\
\hline III & 104 & 18.6 \\
\hline IV & 186 & 33.2 \\
\hline Unknown & 136 & 24.3 \\
\hline \multicolumn{3}{|l|}{ Grade } \\
\hline I & 28 & 5.0 \\
\hline ॥ & 150 & 26.8 \\
\hline III & 215 & 38.4 \\
\hline Unknown & 167 & 29.8 \\
\hline \multicolumn{3}{|l|}{ Surgery } \\
\hline Yes & 178 & 31.8 \\
\hline No & 382 & 68.2 \\
\hline \multicolumn{3}{|l|}{ Chemotherapy } \\
\hline Yes & 177 & 31.6 \\
\hline No & 383 & 68.4 \\
\hline \multicolumn{3}{|l|}{ Radiotherapy } \\
\hline Yes & 328 & 58.6 \\
\hline No & 232 & 41.4 \\
\hline \multicolumn{3}{|c|}{$\begin{array}{l}\text { Abbreviations: } \mathrm{AC}=\text { adenocarcinoma; } \mathrm{GE} \text {-junction=gastroesophageal junction; } \mathrm{SCC}= \\
\text { squamous cell carcinoma. }\end{array}$} \\
\hline
\end{tabular}

and postdiagnosis, 94 patients (17\%) and 16 patients (3\%) used NSAIDs or aspirin only postdiagnosis, respectively.

Table 2 shows the association between patient and tumour characteristics and aspirin or NSAID use. Patients who used aspirin only postdiagnosis were younger compared with prediagnosis and postdiagnosis users and none users $(P=0.005)$. Half of the only postdiagnosis aspirin users were diagnosed with earlystage tumours (stage I and II), in contrast, only $12 \%$ and $32 \%$ of the pre and postdiagnosis aspirin users and none users were diagnosed with stage I or II, respectively. Furthermore, none of the only postdiagnosis aspirin users were diagnosed with stage IV, whereas pre and postdiagnosis aspirin users and none users were more frequently diagnosed with stage IV tumours $(25 \%$ and $45 \%$, respectively).

Pre and postdiagnosis NSAIDs users were younger compared with only postdiagnosis NSAIDs users and none users $(P=0.005)$. Pre and postdiagnosis NSAIDs users were also more frequently diagnosed with early-stage tumours (29\%) than only postdiagnosis NSAIDs users $(22 \%)$ and none users (12\%). Only postdiagnosis NSAIDs users had less stage IV tumours at diagnosis (25\%) than pre and postdiagnosis NSAIDs users (34\%) and none users (45\%). No differences were observed in the distribution of the sex of the patients and the grade of the tumours between the different subgroups $(P>0.05)$.

Survival analysis. Table 3 shows the time-dependent (overall) survival analysis for non-users and users of aspirin. Median followup time was 0.83 years (range $0-13.83$ ); with a median follow-up for deceased patients of 0.55 years (range $0-10.54$ ) and 3.30 years (range 1.0-13.80) for patients still alive at the end of follow-up. Prediagnosis and postdiagnosis use of aspirin was associated with a significant survival gain namely in crude analyses (RR 0.55 (95\% CI $0.41-0.74 ; P<0.001)$ and in multivariable analyses with an RR of 0.44 (95\% CI: $0.31-0.61 ; P<0.001)$ after adjusting for the abovementioned confounders. Furthermore, only postdiagnosis aspirin use was associated with a significant reduction of the overall mortality rate ratio RR 0.15 (95\% CI: $0.07-0.32$; $P<0.001$ ). After adjusting for sex, age, grade, stage, histological type, location of the tumour, treatment and comorbidities the multivariable RR was 0.29 (95\% CI: $0.12-0.70 ; P=0.006)$. Any postdiagnosis aspirin use did also result in a significant better survival outcome with a crude RR of 0.45 (95\% CI $0.34-0.60 ; P<0.001)$ and an adjusted RR of 0.42 (95\% CI: $0.30-0.57 ; P<0.001$ ). Frequent postdiagnosis users of $>30$ dispensings showed a crude RR of 0.56 (95\% CI 0.39-0.82; $P=0.003)$ and a similar adjusted RR of 0.49 (95\% CI: $0.33-0.73$; $P<0.001$ ), whereas frequent users of $>45$ dispensings showed a stronger association with an adjusted RR of 0.36 (95\% CI: $0.21-$ $0.62 ; P<0.001$ (crude RR 0.43 (95\% CI $0.25-0.73 ; P=0.002)$ )). Frequent users of $>20$ dispensings solely postdiagnosis (irrespective of the number prediagnosis) showed a lower crude (RR 0.23 (95\% CI $0.11-0.50 ; P<0.001)$ and adjusted RR of 0.25 (95\% CI: $0.11-0.54 ; P<0.001)$, although the number of users $(n=14)$ was low in this group. Figure 1 shows the survival curve of postdiagnosis aspirin users and none users.

Figure 2 shows the stratified analysis of postdiagnosis aspirin use. Stratified analysis showed the point estimate of aspirin use is lower for females adjusted RR 0.24 (95\% CI: $0.10-0.55 ; P<0.001$ ) than males 0.55 (95\% CI: $0.37-0.80 ; P=0.002)$. The estimate of aspirin users compared with non-users when having early-stage tumours were lower adjusted RR 0.33 (95\% CI: 0.15-0.74; $P=0.007)$ than in patients with late-stage tumours RR 0.56 (95\% CI: $0.35-0.89 ; P=0.01$ ). Moreover, the point estimate in patients with squamous cell carcinoma adjusted RR 0.34 (95\% CI: $0.18-0.63 ; P<0.001)$ was lower than in patients with adenocarcinoma RR 0.43 (95\% CI: $0.28-0.65 ; P<0.001$ ). Furthermore, the point estimates of aspirin use were lower in patients who underwent surgery (RR 0.40 (95\% CI $0.20-0.79$ ) vs RR 0.45 (95\% CI $0.31-0.66)$ in patients who did not undergo surgery), chemotherapy (RR 0.38 (95\% CI 0.17-0.86) vs RR 0.43 (95\% CI $0.30-0.62)$ in patients who were not treated with no chemotherapy) or radiotherapy (RR 0.39 (95\% CI 0.26-0.58) vs RR 0.47 (95\% CI $0.27-0.84$ ) in patients who were not treated with radiotherapy than in untreated patients.

Table 3 shows the time-dependent survival analysis for nonusers and users of NSAIDs. Prediagnosis and postdiagnosis use of NSAIDs did result a significant survival gain with an RR of 0.45 (95\% CI: $0.36-0.57 ; \quad P<0.001$ ). After adjusting for possible confounders the adjusted mortality rate ratio for prediagnosis and postdiagnosis NSAIDs use was significant 0.72 (95\% CI: $0.55-0.95 ; P=0.02)$. Only postdiagnosis NSAIDs use however was not associated with a better survival outcome in the adjusted analyses with an RR of 0.81 (95\% CI: $0.59-1.11 ; P=0.2$ ). Any postdiagnosis NSAIDs was associated with overall survival in the crude analyses (RR 0.61 (95\% CI 0.49-0.78; $P<0.001$ ), however did not result in a significant survival gain in the multivariable analyses with an adjusted RR of 0.84 (95\% CI: $0.66-1.07 ; P=0.2$ ). 
Table 2. Differences in patient and tumour characteristics between none user, prediagnosis \& postdiagnosis and only postdiagnosis users of aspirin or NSAIDs

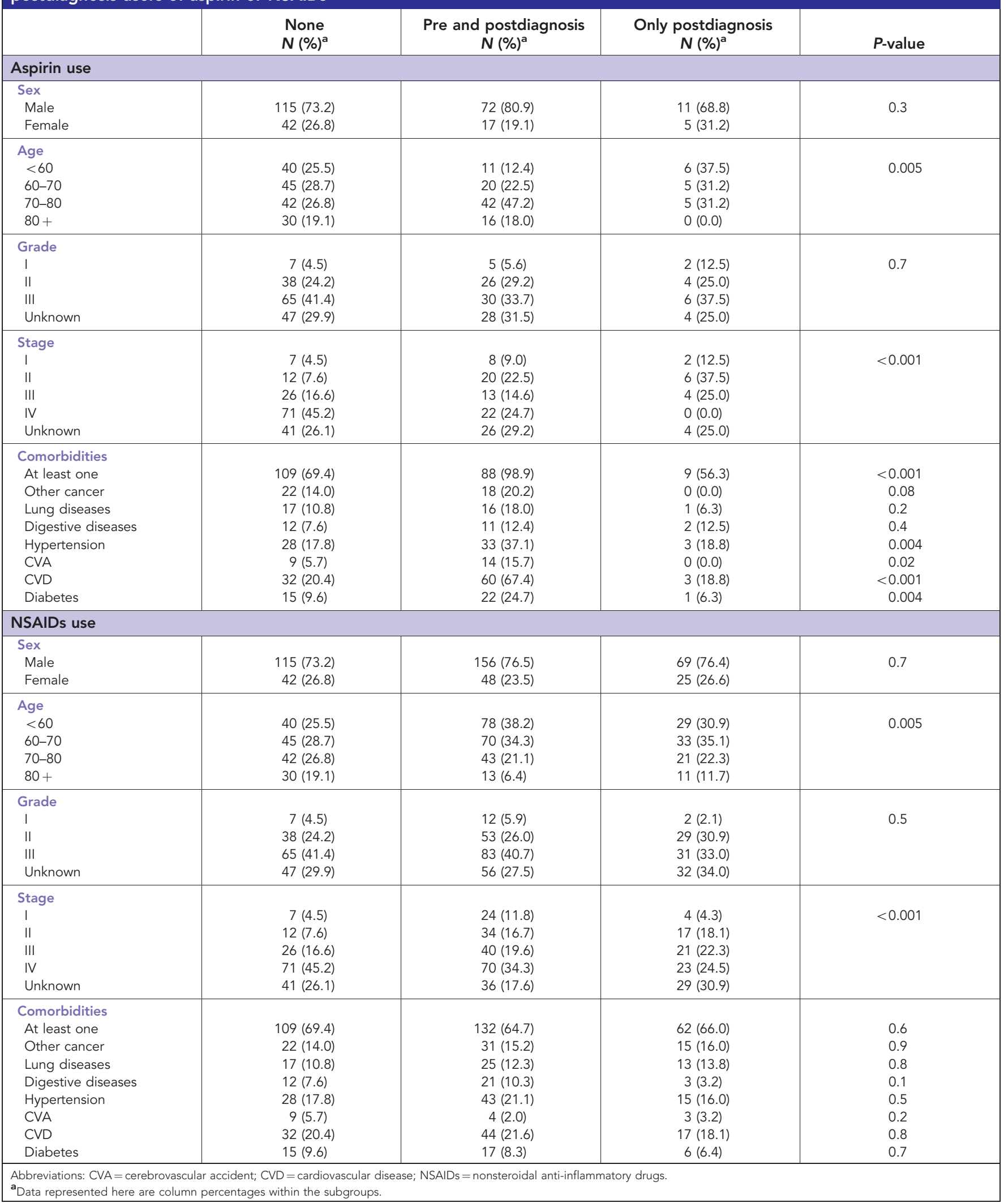

\section{DISCUSSION}

This study shows a possible association between postdiagnosis aspirin use and overall survival in patients with oesophageal cancer. Our results are the first to suggest an association of aspirin use after diagnosis and survival in oesophageal cancer patients. Studies so far focused on the effect of aspirin and NSAIDs use on the risk of developing oesophageal cancer. Also, the effect seems to be aspirin-specific; the postdiagnosis use of NSAIDs had no 
Table 3. Time-dependent overall survival analysis (crude RR and adjusted RR) for non-users and users of aspirin or NSAIDs

\begin{tabular}{|c|c|c|c|c|c|c|}
\hline & $N$ & $E^{\mathrm{a}}$ & Crude rate ratio & $P$-value & Adjusted rate ratio ${ }^{b}$ & $P$-value \\
\hline \multicolumn{7}{|l|}{ Aspirin pre and postdiagnosis } \\
\hline $\begin{array}{l}\text { Non-user } \\
\text { User }\end{array}$ & $\begin{array}{r}157 \\
89\end{array}$ & $\begin{array}{r}129 \\
67\end{array}$ & $\begin{array}{c}\text { Reference } \\
0.55(0.41-0.74)\end{array}$ & $<0.001$ & $\begin{array}{c}\text { Reference } \\
0.44(0.31-0.61)\end{array}$ & $<0.001$ \\
\hline $\begin{array}{l}\text { Non-user } \\
\text { User }\end{array}$ & $\begin{array}{r}157 \\
16\end{array}$ & $\begin{array}{r}129 \\
7\end{array}$ & $\begin{array}{c}\text { Reference } \\
0.15(0.07-0.32)\end{array}$ & $<0.001$ & $\begin{array}{c}\text { Reference } \\
0.29(0.12-0.70)\end{array}$ & 0.006 \\
\hline \multicolumn{7}{|l|}{ Aspirin postdiagnosis $^{c}$} \\
\hline $\begin{array}{l}\text { Non-user } \\
\text { User }\end{array}$ & $\begin{array}{r}157 \\
94\end{array}$ & $\begin{array}{r}129 \\
76\end{array}$ & $\begin{array}{c}\text { Reference } \\
0.75(0.57-1.00)\end{array}$ & 0.05 & $\begin{array}{c}\text { Reference } \\
0.81(0.59-1.11)\end{array}$ & 0.2 \\
\hline \multicolumn{7}{|l|}{ NSAID postdiagnosis ${ }^{c}$} \\
\hline $\begin{array}{l}\text { Non-user } \\
\text { User }\end{array}$ & $\begin{array}{l}157 \\
298 \\
\end{array}$ & $\begin{array}{l}129 \\
222 \\
\end{array}$ & $\begin{array}{c}\text { Reference } \\
0.61(0.49-0.76)\end{array}$ & $<0.001$ & $\begin{array}{c}\text { Reference } \\
0.84(0.66-1.07)\end{array}$ & 0.2 \\
\hline \multicolumn{7}{|c|}{ 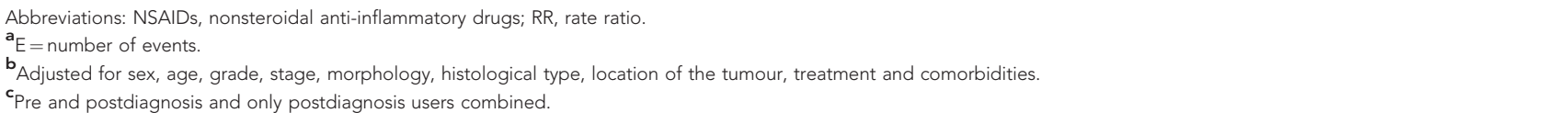 } \\
\hline
\end{tabular}

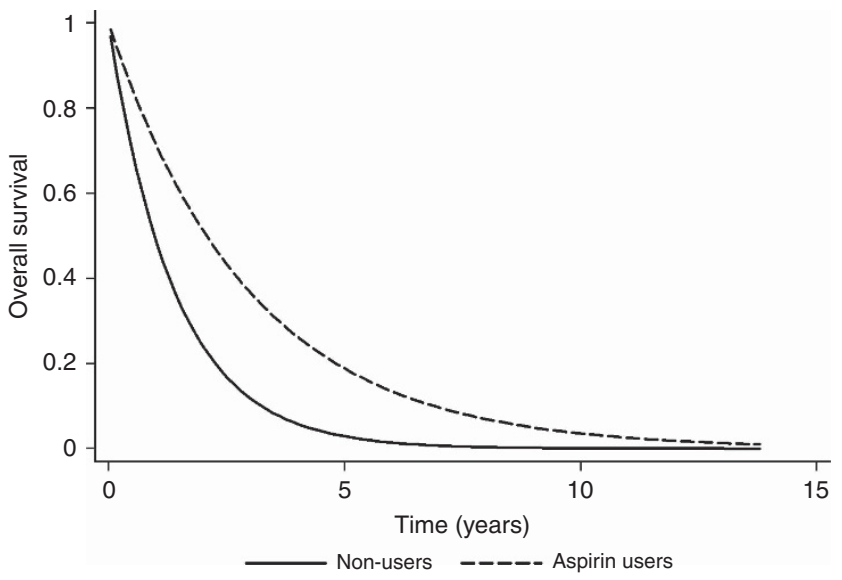

Figure 1. Overall survival curve for postdiagnosis use or non-use of aspirin in patients with oesophageal cancer (pre and postdiagnosis users and only postdiagnosis users combined).

significant effect on outcome. Furthermore, the stratified analysis shows an association of survival with aspirin use consistent among different subgroups, including gender, age and tumour cell type.

Although our results suggest a consistent survival effect of aspirin use in patients with adenocarcinoma and squamous cell carcinoma, the effect might differ between patients with tumours of a different tumour cell type. It is not clear which mechanisms cause this difference in effect of low-dose aspirin use. Furthermore, the survival effect of aspirin use was stronger in only postdiagnosis aspirin users than in 'prediagnosis and postdiagnosis' aspirin users. It is plausible that tumours that developed in presence of low plasma levels of aspirin are also not oppressed by low-dose

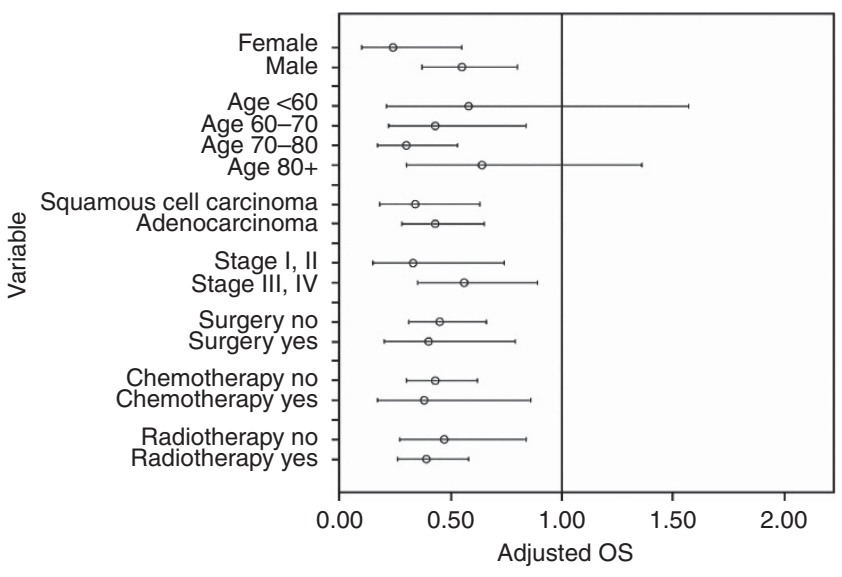

Figure 2. Stratified analysis for postdiagnosis aspirin use (pre and postdiagnosis users and only postdiagnosis users combined).

postdiagnosis aspirin use. The effect might differ between patients with an early-stage tumour RR 0.33 (95\% CI: $0.15-0.74 ; P=0.007$ ) than for late-stage tumours. This might be explained by the assumed predominant anticancer effect of aspirin. Because the effect is also seen in the late-stage tumours, the idea that the effect of aspirin is multifactorial is confirmed (Reimers et al, 2014).

The biological mechanisms involved in the anticancer effect of aspirin are not (yet) fully understood, but recent evidence points out a role of platelets. Aspirin inhibits COX1 expression in platelets, which disrupts platelet activation and the subsequent secretion of $\alpha$-granules containing TGF- $\beta$ and PDGF. These growth factors are involved in the epithelial-mesenchymal transition of circulating tumour cells; thus, aspirin might diminish 
the metastatic potential (Labelle et al, 2011; Lou et al, 2014). Furthermore, aspirin use might also induce COX-independent effects on platelets, for example, by the acetylation of proteins and metabolites, and these other mechanisms could be involved in the chemopreventive effect of aspirin (Dovizio et al, 2013).

Recently, several molecular epidemiological studies have been performed to identify the subset of patients with colorectal cancer who will benefit from aspirin by chemoprevention or as adjuvant therapy and showed in two studies that the observed significant survival gain of postdiagnosis aspirin use was present in mutatedPIK3CA tumours, but not in PIK3CA wild-type tumours (Liao et al, 2012; Domingo et al, 2013). However, PGTS2-specific inhibition by rofecoxib did not improve the relapse-free survival in PIK3CAmutated tumours $(P=0.66)$ (Domingo et al, 2013). In contrast, the analysis of 999 colorectal tumour blocks resected from 2002 to 2008 in the Netherlands showed no association of survival benefit of postdiagnosis use of aspirin with tumours with mutated-PIK3CA and COX2 expression. The survival benefit of low-dose postdiagnosis aspirin use did depend on the presence of another biomarker; patients with tumours with HLA Class I antigen expression showed a significant survival gain, but patients with tumours without HLA Class I antigen expression did not (Reimers et al, 2014).

The value of PIK3CA-mutation status and COX2 expression levels as biomarkers in colon cancer remains inconclusive (Liao et al, 2012; Reimers et al, 2014). Also, the mutation frequency of PIK3CA in oesophageal squamous cell carcinomas and adenocarcinomas is lower, namely $4.5 \%$ (Song et al, 2014), respectively, $6.0 \%$ (Phillips et al, 2006) than the reported mutation rates of 11-17\% (Liao et al, 2012; Nishihara et al, 2013; Rosty et al, 2013; Reimers et al, 2014) in the tumour specimens of colorectal carcinomas. Therefore, future molecular pathological epidemiological studies should focus on a combination of potential biomarkers to examine the therapeutic effect of postdiagnosis aspirin use in patients with oesophageal cancer.

The present observational study has several limitations. First, as baseline characteristics (which are associated with survival) of nonusers and aspirin users differ, the survival effect of aspirin could also partially be caused by healthy-user bias. As shown in Table 1, the users are younger and have a lower stage of disease at the moment of diagnosis, which are associated with survival; however, they are also more often diagnosed with comorbidities. We adjusted for these factors in the multivariable analyses, but residual confounding may be present and as a result of the lower number of users it remains questionable if we adjusted sufficiently, especially in the group of 'only postdiagnosis' users. However, the survival analysis of the 'prediagnosis and postdiagnosis' also resulted in a strong survival effect with an adjusted RR of 0.44 (95\% CI: $0.31-$ 0.61 ). The analyses of frequent users showed a stronger association in frequent users, although only present in the users with a high number of dispensings. A second limitation of the present study is the low number of 'only postdiagnosis' aspirin users in the patient cohort, which might influence the results. Larger studies with a higher number of postdiagnosis aspirin users are needed to confirm the results. A third limitation of the study could be 'over the counter use' of aspirin. However, low-dose aspirin is mainly available on dispensing in the Netherlands, but we cannot rule out the possibility of over the counter use of (higher) aspirin doses, which are available as we did not have information regarding the use of aspirin or NSAIDs by patients at home. At last, aspirin is usually prescribed by the means of cardiovascular chemoprevention, thus confounding by indication could be a problem. It is however not likely that the indicators of an elevated risk of cardiovascular disease provide user patients with a beneficial survival prognosis with respect to non-user patients. Also, the survival effect of aspirin use cannot only be explained by a reduction of cardiac events; in the meta-analysis of six primary prevention trials and 16 secondary prevention trials by Baigent $\mathrm{C}$ et al the survival gain of aspirin use was lower than the survival gain observed in the present study and showed a pooled gain (for primary and secondary prevention of vascular disease) of $\sim 5 \%$ (Baigent et al, 2009). One of the major strengths of our study was the use of a database of dispensed medication, by which we avoided recall-bias.

Our study suggests that patients with oesophageal cancer might benefit more from postdiagnosis aspirin use than patients with colon cancer. These results are in line with previous data of Rothwell's study of the long-term risk of cancer-related death in daily aspirin users; the 20-year cancer-related mortality was lower for patients with oesophageal cancer 0.42 (95\% CI: $0.25-0.71)$ than for patients with colon cancer 0.60 (95\% CI: 0.45-0.81) (Rothwell et al, 2011).

In the future, a randomised clinical trial is needed to verify our epidemiological observations of the benefits of postdiagnosis aspirin use in patients with oesophageal cancer. Furthermore, it is important to identify the subgroups in which the benefits of lowdose postdiagnosis aspirin might outweigh the risks of severe adverse effects like gastrointestinal bleeding. The identification of biomarkers could predict in which patients low-dose aspirin has a significant survival effect. Because aspirin is already a well-tested and cheap drug, it could have a beneficial clinical impact when introduced as an adjuvant therapy in patients with oesophageal cancer.

\section{ACKNOWLEDGEMENTS}

ECR of Comprehensive Cancer Center Netherlands and PHARMO Database Network of the PHARMO Institute.

\section{CONFLICT OF INTEREST}

The authors declare no conflict of interest.

\section{REFERENCES}

Abnet CC, Freedman ND, Kamangar F, Leitzmann MF, Hollenbeck AR, Schatzkin A (2009) Non-steroidal anti-inflammatory drugs and risk of gastric and oesophageal adenocarcinomas: results from a cohort study and a meta-analysis. Br J Cancer 100(3): 551-557.

Algra AM, Rothwell PM (2012) Effects of regular aspirin on long-term cancer incidence and metastasis: a systematic comparison of evidence from observational studies vs randomised trials. Lancet Oncol 13(5): 518-527.

Baigent C, Blackwell L, Collins R, Emberson J, Godwin J, Peto R, Buring J, Hennekens C, Kearney P, Meade T, Patrono C, Roncaglioni MC, Zanchetti A (2009) Aspirin in the primary and secondary prevention of vascular disease: collaborative meta-analysis of individual participant data from randomised trials. Lancet 373(9678): 1849-1860.

Bastiaannet E, Sampieri K, Dekkers OM, de Craen AJ, van Herk-Sukel MP, Lemmens V, van den Broek CB, Coebergh JW, Herings RM, van d V, Fodde R, Liefers GJ (2012) Use of aspirin postdiagnosis improves survival for colon cancer patients. Br J Cancer 106(9): 1564-1570.

Bruno A, Dovizio M, Tacconelli S, Patrignani P (2012) Mechanisms of the antitumoural effects of aspirin in the gastrointestinal tract. Best Pract Res Clin Gastroenterol 26(4): e1-e13.

Buskens CJ, van Rees BP, Sivula A, Reitsma JB, Haglund C, Bosma PJ, Offerhaus GJ, van Lanschot JJ, Ristimaki A (2002) Prognostic significance of elevated cyclooxygenase 2 expression in patients with adenocarcinoma of the esophagus. Gastroenterology 122(7): 1800-1807.

Corley DA, Kerlikowske K, Verma R, Buffler P (2003) Protective association of aspirin/NSAIDs and esophageal cancer: a systematic review and metaanalysis. Gastroenterology 124(1): 47-56.

Din FV, Theodoratou E, Farrington SM, Tenesa A, Barnetson RA, Cetnarskyj R, Stark L, Porteous ME, Campbell H, Dunlop MG (2010) 
Effect of aspirin and NSAIDs on risk and survival from colorectal cancer. Gut 59(12): 1670-1679.

Domingo E, Church DN, Sieber O, Ramamoorthy R, Yanagisawa Y, Johnstone E, Davidson B, Kerr DJ, Tomlinson IP, Midgley R (2013) Evaluation of PIK3CA mutation as a predictor of benefit from nonsteroidal anti-inflammatory drug therapy in colorectal cancer. J Clin Oncol 31(34): 4297-4305.

Dovizio M, Bruno A, Tacconelli S, Patrignani P (2013) Mode of action of aspirin as a chemopreventive agent. Recent Results Cancer Res 191: 39-65.

Dubecz A, Gall I, Solymosi N, Schweigert M, Peters JH, Feith M, Stein HJ (2012) Temporal trends in long-term survival and cure rates in esophageal cancer: a SEER database analysis. J Thorac Oncol 7(2): 443-447.

Huang TB, Yan Y, Guo ZF, Zhang XL, Liu H, Geng J, Yao XD, Zheng JH (2014) Aspirin use and the risk of prostate cancer: a meta-analysis of 24 epidemiologic studies. Int Urol Nephrol 46(9): 1715-1728.

Jayaprakash V, Menezes RJ, Javle MM, McCann SE, Baker JA, Reid ME, Natarajan N, Moysich KB (2006) Regular aspirin use and esophageal cancer risk. Int J Cancer 119(1): 202-207.

Jemal A, Bray F, Center MM, Ferlay J, Ward E, Forman D (2011) Global cancer statistics. CA Cancer J Clin 61(2): 69-90.

Labelle M, Begum S, Hynes RO (2011) Direct signaling between platelets and cancer cells induces an epithelial-mesenchymal-like transition and promotes metastasis. Cancer Cell 20(5): 576-590.

Langley RE, Burdett S, Tierney JF, Cafferty F, Parmar MK, Venning G (2011) Aspirin and cancer: has aspirin been overlooked as an adjuvant therapy? Br J Cancer 105(8): 1107-1113.

Liao X, Lochhead P, Nishihara R, Morikawa T, Kuchiba A, Yamauchi M, Imamura Y, Qian ZR, Baba Y, Shima K, Sun R, Nosho K, Meyerhardt JA, Giovannucci E, Fuchs CS, Chan AT, Ogino S (2012) Aspirin use, tumor PIK3CA mutation, and colorectal-cancer survival. N Engl J Med 367(17): 1596-1606.

Liu JF, Jamieson GG, Wu TC, Zhu GJ, Drew PA (2009) A preliminary study on the postoperative survival of patients given aspirin after resection for squamous cell carcinoma of the esophagus or adenocarcinoma of the cardia. Ann Surg Oncol 16(5): 1397-1402.

Lou XL, Deng J, Deng H, Ting Y, Zhou L, Liu YH, Hu JP, Huang XF, Qi XQ (2014) Aspirin inhibit platelet-induced epithelial-to-mesenchymal transition of circulating tumor cells (Review). Biomed Rep 2(3): 331-334.

Nishihara R, Lochhead P, Kuchiba A, Jung S, Yamauchi M, Liao X, Imamura Y, Qian ZR, Morikawa T, Wang M, Spiegelman D, Cho E, Giovannucci E, Fuchs CS, Chan AT, Ogino S (2013) Aspirin use and risk of colorectal cancer according to BRAF mutation status. JAMA 309(24): 2563-2571.

Phillips WA, Russell SE, Ciavarella ML, Choong DY, Montgomery KG, Smith K, Pearson RB, Thomas RJ, Campbell IG (2006) Mutation analysis of PIK3CA and PIK3CB in esophageal cancer and Barrett's esophagus. Int J Cancer 118(10): 2644-2646.

Reimers MS, Bastiaannet E, Langley RE, van ER, van Vlierberghe RL, Lemmens VE, van Herk-Sukel MP, van WT, Fodde R, Kuppen PJ, Morreau H, van de Velde CJ, Liefers GJ (2014) Expression of HLA class I antigen, aspirin use, and survival after a diagnosis of colon cancer. JAMA Intern Med 174(5): 732-739.

Rosty C, Young JP, Walsh MD, Clendenning M, Sanderson K, Walters RJ, Parry S, Jenkins MA, Win AK, Southey MC, Hopper JL, Giles GG, Williamson EJ, English DR, Buchanan DD (2013) PIK3CA activating mutation in colorectal carcinoma: associations with molecular features and survival. PLoS One 8(6): e65479.

Rothwell PM, Fowkes FG, Belch JF, Ogawa H, Warlow CP, Meade TW (2011) Effect of daily aspirin on long-term risk of death due to cancer: analysis of individual patient data from randomised trials. Lancet 377(9759): $31-41$.

Sadeghi S, Bain CJ, Pandeya N, Webb PM, Green AC, Whiteman DC (2008) Aspirin, nonsteroidal anti-inflammatory drugs, and the risks of cancers of the esophagus. Cancer Epidemiol Biomarkers Prev 17(5): 1169-1178.

Song Y, Li L, Ou Y, Gao Z, Li E, Li X, Zhang W, Wang J, Xu L, Zhou Y, Ma X, Liu L, Zhao Z, Huang X, Fan J, Dong L, Chen G, Ma L, Yang J, Chen L, He M, Li M, Zhuang X, Huang K, Qiu K, Yin G, Guo G, Feng Q, Chen P, Wu Z, Wu J, Ma L, Zhao J, Luo L, Fu M, Xu B, Chen B, Li Y, Tong T, Wang M, Liu Z, Lin D, Zhang X, Yang H, Wang J, Zhan Q (2014) Identification of genomic alterations in oesophageal squamous cell cancer. Nature 509(7498): 91-95.

van Herk-Sukel MP, van de Poll-Franse LV, Lemmens VE, Vreugdenhil G, Pruijt JF, Coebergh JW, Herings RM (2010) New opportunities for drug outcomes research in cancer patients: the linkage of the Eindhoven Cancer Registry and the PHARMO Record Linkage System. Eur J Cancer 46(2): 395-404.

Zhang L, Wu YD, Li P, Tu J, Niu YL, Xu CM, Zhang ST (2011) Effects of cyclooxygenase-2 on human esophageal squamous cell carcinoma. World J Gastroenterol 17(41): 4572-4580.

Zimmermann KC, Sarbia M, Weber AA, Borchard F, Gabbert HE, Schror K (1999) Cyclooxygenase-2 expression in human esophageal carcinoma. Cancer Res 59(1): 198-204.

This work is published under the standard license to publish agreement. After 12 months the work will become freely available and the license terms will switch to a Creative Commons AttributionNonCommercial-Share Alike 4.0 Unported License.

Supplementary Information accompanies this paper on British Journal of Cancer website (http://www.nature.com/bjc) 